\title{
The Face of the Beast: Bestial Descriptions and Psychological Response in Horror Literature
}

\author{
Jonathan W. Thurston' \\ English and Animal Studies, Michigan State University, \\ United States
}

\section{Abstract}

Current scholarship surrounding the predator mythos in culture and literature suggests a distinctive binary of wild-domestic. Scholars often argue that the uniquely terrifying aspect of the predator is in its unconscious capacity to invade our standards of civilization, disrupt order, and pass our final frontier of fear: that of being eaten alive. Other scholars, too, tend to read the terror of these predators with an almost colonial analysis, centering around the concept of the predators' ulterior motive to flip the cultural hierarchy of human above animals. However, what these scholars often neglect are the physiological and evolutionary drives that ultimately construct a genetic response to these predators' general anatomical outlines and features. As we undertake the crucial work of understanding humans' perceptions of their place in their environment, it is important to recognize that, aside from discussions of culturally constructed paradigms of dominance, we too are animals, with primal responses to our environmental conditions. These instinctive responses must be acknowledged as playing a part in our view of the "wild." The scholarship on predator-human interactions necessitates a close study of such relations. In horror texts-literature, films, video games, and other media-the depiction of fearful "beasts" relies on anatomically deconstructing the image of the predator to highlight key predatory features that generate instinctive responses in the audience. On display, in the horror genre, is the anatomy of our fear of predators.

Keywords: animals in literature, animal representations, evolution, horror literature, physiological responses, predators

1 Corresponding author: thurst39@msu.edu 


\section{Introduction}

The beast approaches. Its fangs are dripping; its eyes are gleaming; and a low growl emits from its throat. Behold the monstrous beast. As far back as our mythic history documents, animal monsters ${ }^{2}$ have raged across our culture and literature. They become the objects (and subjects) of transformation in Ovid's Metamorphoses. They line the medieval bestiaries in a combination of myth and science. They terrorize the seas of Renaissance maps as both adornments and very real warnings: Here, there be dragons. And, in recent years, we have new monsters: ants that are 30 feet high in Gordon Douglas's 1954 film Them!, sharks that devour ignorant swimmers in Peter Benchley's award-winning novel Jaws (1974), zombie companion animals in Stephen King's Pet Sematary (1983), and a pack of killer wolves in the 2011 film starring Liam Neeson, The Grey.

As one can easily imagine, these monsters appear rather frequently in the genres of horror and thriller literature. They can be minor pests, such as the half-decomposed dogs of the Resident Evil video game series (Mikami, 1996-present), or they can be titular antagonists, such as in the often comedic horror film Eight-Legged Freaks (Elkayem, 2002). In these types of works, the monsters are rarely multifaceted characters. At no point in Black Water (Traucki \& Nerlich, 2007) are we to feel sorry for the man-eating crocodile. We do not find ourselves analyzing the ethics of predation with the velociraptors in Michael Crichton's Jurassic Park (1990). So, despite the fact that, really, most of these fictional beasts are quite similar from a narratological stance at least, how is it that they continue to inspire such terror? How can we read a purely biological description of a predator's anatomical features in a novel and connect even these few words with as strong an emotion as fear? What makes these monsters an asset for the horror genre?

Current scholarship surrounding the predator mythos in culture and literature suggests a distinctive binary of wild-domestic. Scholars often argue that the uniquely terrifying aspect of the predator is in its unconscious capacity to invade our standards of civilization, disrupt any semblance of life, and pass the final frontier of fear for us; being eaten alive. Victorian scholar Claire McKechnie (2012) speaks of the cultural fear toward spiders and claims that the major contributing factor to their negative portrayal is due to their violation of human boundaries:

As representative of the colonial aggressor, the spider trope gave legitimacy to, while expressing fears about, the authority and legality of the imperial endeavour. The spider represented the transgression of boundaries between inside and outside, home and abroad, self and other, security and danger. (p. 507)

2 Throughout this paper, I will use the following terms almost interchangeably: "beast," "monster," "animal monster," "predator," and "carnivore." While there are certain nuanced differences (e.g., "predator" has the connotation of hunting, while "carnivore" has the connotation of devouring), whenever I refer to any of these things, I am intentionally excluding human "monsters" and animal-human hybrids, such as werewolves and mermaids. 
Here, the spider embodies this invasion of the domestic space. Australian cinema scholar Catherine Simpson tackles the problem of what she calls "eco-horror" films, such as the aforementioned Black Water, in which nature lashes out as an aggressive force to snuff out humanity as a form of Gaia-ic vengeance. She considers the terror of these conquering predators to be due, at least in part, to the threat they pose to our anthropocentric conception of the world:

What these examples of Australian eco-horror display, where humans become prey for animals, is not always an acceptance of our "ecological identity," but more the existence and agency of the "more-than-human" world. (Simpson, 2010, p. 52)

Here, predators in horror manifest as not just colonial invaders as the Victorian spider but also as conquerors, seeking to shift our cultural balance to one more subordinate to animal space. Other scholars, too, tend to read the terror of these predators with an almost colonial analysis, centering around the concept of the predators' ulterior motive to flip the cultural hierarchy of human above animals. ${ }^{3}$

However, what these scholars often neglect are the physiological and evolutionary statistics that ultimately reveal there is a genetic response to these predators' general anatomical outlines and features. As we undertake the crucial work of understanding humans' perceptions of their place in their environment, it is important to recognize that, aside from discussions of culturally constructed paradigms of dominance, we too are animals, with primal responses to our environmental conditions. These instinctive responses must be acknowledged as playing a part in our view of the "wild." Zoologists and animal studies scholars ${ }^{4}$ have yet to meld each other's fields of concentration into a cohesive work on the physiological response to predators in the rhetorical mode of literary description of these predators. Even in film, video games, and graphic novels, the anatomical forms of the predators can be deconstructed to highlight certain predatory features that generate instinctive responses. This dearth of zoohistoricist scholarship ${ }^{5}$ on predator-human interactions necessitates a close study of such relations, especially in the context of horror narrative. Horror literature-including films, novels, graphic novels, and video games-relies on anatomically deconstructing the image of the predator in such a way that it appeals not to a scientifically realistic description but to the instinctive psychological reduction of predators that humans experience. The way that this article defines "instinct" is informed largely by cultural evolution writers, such as Paul A. Trout (2011) and Joseph Henrich (2016). So, when discussing instinct and psychological or physiological responses, I use wide strokes as a means of generating a point of departure from which other researchers can build. Horror literature itself is,

\footnotetext{
3 For examples of these other studies, see Lucic (2014), Neff (2016), and Soles (2014) in Further reading.

4 "Animal studies" here implies the humanities approach to the study of animals, including but not limited to the schools of philosophy, ethics, literature, and history.

5 "Zoohistoricism" here involves the study of animals through a natural historian lens, especially in the context of the humanities as affected by science.
} 
of course, a very broad term, and I am using it the way Dominic Strinati (2000) defines it as a genre that "represents the need for suppression if the horror shown is interpreted as expressing uncomfortable and disturbing desires which need to be contained" (p. 82). Many of the terms, and ways I use them, will become clear through not only my analysis of the current research but also through the literary case studies following.

\section{In our blood}

Before actually delving into fictional works, it is crucial to set up a foundation of understanding human psychophysiology regarding predator interaction. This foundation will help in understanding just how thoroughly and completely the instinctive response to predators is not just toward a holistic image of the predator but in response to a predator's individual anatomical parts. When we understand the psyche of fear responses toward predators, we can apply that knowledge more confidently to anatomical descriptions of predators in horror literature.

The first major concept of human response to predators is in what can be called the "triggers of fear." These are essentially physiological sensitivities to specific environmental stimuli. Professor emeritus Paul A. Trout has done extensive research on the connection between Joseph Campbell's "mythic imagination" and evolutionary responses to predators. He talks about newborn chicks having comparable physiological sensitivities to humans:

They will scurry in fright when a cardboard cutout of a hawk that has been placed on a string moves across a barnyard. But if the cutout is made to go backward or if the shape is changed to resemble a non-predatory bird, the chicks show no fear. The chicks have been programmed by evolution to fear a certain shape and trajectory of motion rather than a specific predator. (Trout, 2011, p. 67)

These same types of categories exist for humans. Trout elaborates some of these individual traits we recognize not just taxonomically_ "this is a predator" — but also through fear response:

Our ancient ancestors were primed by evolution to associate these features with a potential threat to their lives. To feel fear, they did not have to identify the specific kind of animal — they simply had to notice any of these physical features: staring eyes, an open mouth, flashing sharp teeth, a lolling tongue-these all spelled "danger," "predator." (p. 77)

Aside from these facial features, Trout includes our fears of menacing movements, blood, bones, certain sounds, tracking signs, and darkness. 
It is crucial to observe that these stimuli are what construct our instinctive response to predators, not taxonomy. Hans Kruuk (2002), another predator specialist, conducted a study on wildebeests' responses to a stuffed hyena:

But the wildebeest just seemed to laugh at my experiment, and totally ignored it. Later I realized that these animals react to a host of small signals from the predator, to how it walks, which way it looks, whether it has just eaten, and more. (p. 172)

And he notes that such concepts translate to humans, especially:

A specific example is the behavior of people to one of their classic predators, the lion ... When visitors on bush-walking safaris are taught what to do when walking in wild country in Africa, they have to be persuaded hard not to run away when a lion approaches, but to stand their ground or climb a tree. It is very difficult to get people to do this because of the almost irresistible urge to flee, which could be fatal. (pp. 175-176)

This type of fear is captivating because it overrides logos in favor of the more bestial pathos. This anatomically reductive instinct we possess can be stronger than what we are told will keep us alive.

So, why do we have this instinctive fear? What is its evolutionary reasoning? A major aspect of it is fairly straightforward: we are scared of being eaten alive. David Quammen (2003, p. 274) argues that our fear of predators is not some metaphorical fear related to dominance-submission. Instead, through his engagement with Shepard (1997), he argues quite the opposite: "Such fear arises from signals beyond memory, beyond oral tradition, beyond ancient poetry and cave art ... it's programmed into human DNA." So, here we see how this kind of fear is not merely cultural, but also instinctive.

With this instinctive anatomical reduction (from here on, IAR) of predators, we create this almost hyperreal identification of that which we fear. Even as we know quite logically that dragons are not real and that dinosaurs no longer roam the earth, we can watch something like Jurassic Park or even Ridley Scott's Alien series and be afraid of these monsters that do not exist in reality. Cultural scientist Matt Kaplan (2012) argues that it is often a combination of real predatory features and the metaphorical danger of the unknown that keeps these monsters terrifying, especially in the context of Jurassic Park:

The combination of such realistic traits in the dinosaurs along with the message that natural systems are totally unpredictable reinforces an image of the natural world as inherently dangerous to interfere with. (p. 188) 
Watching the film Jurassic Park, we can break it down into the core IAR elements that Trout introduced. We see the flashing eyes, the sharp claws, the open mouth. So, altogether, predators are not just a taxonomical entity but also a subconscious construct composed of clearly identifiable anatomical parts.

When we come to look at the genre of horror literature, IAR appears a surprising amount. This genre in popular fiction does not lend its animal antagonists with the same mode of technical accuracy with which it renders Gothic architecture or clothing details. The predator thrives in outline and in focus of the IAR parts.

\section{In our texts}

In the examination of predators in texts (all cultural expressions: literature, film, video games, arts, etc.) of the horror genre, the narratological role of the predator takes certain precedence. In many cases, the predator is the primary antagonist, for example, the titular monsters of Jaws, Cujo, and Arachnophobia. In other works, the predators occupy the role of minion or even omen, such as the raptor imagery pervasive in Alfred Hitchcock's film Psycho (1960) or the bees of Bernard Rose's film Candyman (1992). Sometimes, this role is compounded more so that we have an anthropomorphic villain rather than typical predator antagonism. Prime examples include any werewolf novel or even Ridley Scott's Alien series (1979-2017), in which the aliens have their own system of communication. However, in the more frequent case of the bestial predator, the descriptions become anatomically reductive, centering on the physical characteristics of humans' IAR-based response of fear. In this way, horror writers are not just tackling the general question of what people fear but are actually tapping into genetic coding of humans predator recognition.

\section{On our pages}

One example of this is in Stephen King's best-selling novel Cujo (1981). When the Saint Bernard dog starts showing severe symptoms of rabies, the character Brett perceives him as almost wolf-like: "The Saint Bernard's big, sad eyes were now reddish and stupid and lowering: more pig's eyes than dog's eyes ... His muzzle was wrinkled back in a terrible mock grin that froze Brett with horror" (p. 98). Despite King's usually meticulous attention to details such as brand names, colors, and marks of degradation, ${ }^{6}$ the Saint Bernard is the least realistically described and the most mythological in proportion. The earliest iteration of the Saint Bernard in the novel is actually in the young Tad Trenton's nightmarish, imaginary conversion of things in his closet into a monstrous canid: "Low to the ground it was, with huge shoulders bulking above its cocked head, its eyes amber-glowing pits ... He heard its

6 For more information on King's use of meticulous detail, see Davidson (2015) in Further reading. 
purring growl; he smelled its sweet carrion breath" (p. 4). Throughout the novel, the Saint Bernard retains this reductive description. We rarely see what colors its fur is. We rarely see precisely how tall it is. We rarely see any realistic portrayal of the dog.

Another great case study is in Clive Barker's Books of Blood series. Probably the most renowned of his animal antagonists is the great sow of "Pig Blood Blues." However, the predator aspects of the pig are confounded by heavy anthropomorphism as the animal is seemingly possessed and able to speak in a human's voice. A strong example of a Barkerian predator is in his short story "Twilight at the Towers." In this story, an antagonistic magician is able to summon a mystical tiger. The protagonist first encounters the tiger as it is devouring a witness of a prior murder:

She was there. But so was the tiger ... Its eyes were molten; its open maw impossibly large. And there, already in its vast throat, was Barbara. He met her eyes out of the tiger's mouth, and saw a flicker of comprehension in them that was worse than any madness. Then the beast threw its head back and forth to settle its prey in its gut. (1991, p. 165)

Here, again we have a predator reduced to eyes and a mouth. Even in other descriptions of the beast in the story, there is more emphasis on the glowing eyes and gaping maw than on the fact that the animal is striped.

A third case study is in Peter Benchley's 1974 novel, Jaws. As Benchley states in his nonfiction work on sharks, Shark Trouble (2002), he had a large hand in America's cultural mythos on sharks (pp. 32-41). His infamous shark tale encapsulates the innate fear of sharks, not to mention other denizens of the deep. So, how does Benchley describe the fish? In the novel's opening paragraph, it goes back to the eyes, the forward motion, and the titular jaws:

The great fish moved silently through the night water, propelled by short sweeps of its crescent tail. The mouth was open just enough to permit a rush of water over the gills. There was little other motion ... The eyes were sightless in the black, and the other senses transmitted nothing extraordinary to the small, primitive brain ... it survived only by moving. (1974, p. 3)

Again, we have no description of the body of the beast, just those particular anatomical features in detail.

So, what we have is an almost subconscious writing formula for the descriptions of horrific predators, reducing them to a handful of specific criteria, rather than painting a realistic image of the monster. And this concept manifests in a clearly quantitative way, as observed in Table 1. 
Table 1. Statistical appearances of instinctive anatomical reduction $(\mathrm{IAR})$ in predator descriptions of five horror works

\begin{tabular}{|l|c|c|c|c|c|c|}
\hline \multirow{2}{*}{ Title } & \multicolumn{6}{|c|}{ Instances throughout work regarding predator descriptions } \\
\cline { 2 - 7 } & Eyes & $\begin{array}{c}\text { Maw/ } \\
\text { teeth }\end{array}$ & Claws & Growling & Movement & $\begin{array}{c}\text { Non-IAR } \\
\text { descriptors }\end{array}$ \\
\hline Jaws & 8 & 52 & - & - & 12 & 11 \\
\hline Cujo & 21 & 24 & 10 & 24 & 11 & 10 \\
\hline "Twilight at the Towers" & 2 & 11 & 43 & 8 & 5 & 3 \\
\hline Winter Wolves* & 31 & 18 & 11 & 16 & 13 & 12 \\
\hline The Hatching† & 0 & 22 & 15 & - & 37 & 16 \\
\hline
\end{tabular}

* This book (Wescott, 1989) was likely an inspiration for the 2011 film starring Liam Neeson, The Grey (Carnahan, 2011), discussed below.

† This book is a progressive apocalyptic novel featuring deadly spiders (Boone, 2016).

The data in Table 1 reveal that primary trends in horror literature limit descriptions of predators to IAR, highlighting the eyes, motion and trajectory, jaws, and claws of the beast as opposed to other characteristics such as musculature, fur dynamics, or even coloration. One could easily examine these findings and claim they are simply prominent physical attributes of these animals and therefore would have nothing to do with an inherited perception of predator anatomy. However, this starkly contrasts with similarly placed descriptions of fantastical and anthropomorphic monstersfor example, werewolves, the great sow of "Pig Blood Blues," or the many speaking monsters of the Harry Potter (Rowling, 1997-2007) universe-and completely human antagonists. Even with something like vampires, more attention is often given to their clothes or their intelligence than to their fangs and claws.

Still, this analysis creates an approach for quantifying predator descriptions in horror novels and short stories. But how do we analyze such appearances of predators in elements of popular literature outside of novels and short stories, such as films, graphic novels, and video games?

\section{In our visions}

Often, in these visual mediums, the predators occupy a liminal space in the artistic style of the depiction. As subjects and objects of horror, the predator must become more terrifying than it appears in reality. After all, it must become what Angela Carter (1993) has called the "carnivore incarnate" (pp. 110-118). In order to achieve this transformation, the artistic rendering often reduces the predator to a dark shape with glowing eyes and dripping fangs. (In the rare case that the predator does have more intimate detail, it is to highlight a fantastic monstrosity rather than a scientific characterization of the predator.) 
A great starting place to examine this is Catherine Hardwicke's 2011 film, Red Riding Hood. In a film where color matters significantly in the plot-even in the name of the tale-we would expect a lot of separation of the wolf from the background. However, most of the time in the film, the wolf is a black silhouette on dark backgrounds. The only clear detail about the wolf for most of the film is his glowing eyes (occasionally we get a glimpse of his open jaws, too). Most of his movements are slow and deliberate as he hounds each of his human prey with cold intentionality. In this way, we have even a visual wolf relegated to the "rules" of IAR in horror.

This practice of silhouetting the monster in general with focus on the eyes and maw is far from rare in horror films focusing on predators. Here are a few examples:

First, there is the resurrected cat, Church, from the film Pet Sematary (Lambert, 1989). Multiple times in the film, Church is portrayed as a dark cat, typically in dark environments. In almost every shot of the uncanny cat, its mouth is open revealing fangs, its ears are back, fur bristled, and eyes glowing yellow. The original trailer for the movie shows this, too. ${ }^{7}$

Next, there is the wolf pack from the film The Grey (Carnahan, 2011). In one scene, the survivors of the plane accident huddle around a campfire in the frozen woods. Outside of the fire, there is just darkness, and all the survivors can see are pairs of eyes staring back at them, though one pair of eyes ventures a little closer to bare its fangs. ${ }^{8}$

Next is the Tyrannosaurus rex from Jurassic Park (Spielberg, 1993). What many might remember about this film is one of the early scenes when the park's electric security systems shut down and the monstrous T-rex attacks the main characters on the storm-drenched road. In this scene, the dinosaur is constantly framed by darkness and lightning, his mouth opens in a toothy roar, and his eyes are glowing. ${ }^{9}$

In video games, predators often become a touch more realistic than their film counterparts. This is often due to the player being able to move the camera at their discretion, so the creator cannot limit the player's view to a certain perspective of the predator. Essentially, the animal must look terrifying from all angles. Two of the major ways to accomplish this three-dimensional terror are to focus on the beast's trajectory and motion and to give the predator bestial sounds.

\footnotetext{
7 See this link for the original trailer (timestamp 0:26): youtube.com/watch?v=JMao8sg4DPA

8 An example of this can be found in the original trailer for this film (timestamp 0:57): youtube.com/ watch? $=\mathrm{eUP} 5 \mathrm{Vr} 01 \mathrm{Bv} Y$

9 While the trailer never shows the full face of this dinosaur, it does show the glowing eye up close (timestamp 1:47): youtube.com/watch?v=Bim7RtKXv90
} 
For example, in the case of the Silent Hill series (Toyama, 1994-2019), there is a canine monster-presumably undead-reminiscent of a greyhound to signify its speed. The creature, known as the Groaner, is cadaverous, emaciated, and hunts the player, often in packs. It is distinguished not just by its appearance but by its characteristic "groaning" sounds and the rapid speed with which it chases the player. So, even while the camera rarely gets to focus in on the Groaner, we still get that IAR response through its trajectory and motion and its sounds.

This visceral rendering of predators also appears in the video game Bloodborne (Miyazaki, 2015), in which we have a pig-like monster that is mostly depicted in low detail except for its gaping maw and stalking trajectory. It is massive in size and covered in deep, wrinkling folds of flesh. The folds are so large that they seem to cover its eyes, and its salivating mouth is open, revealing red gums and sharp rows of teeth. Its depiction is grotesque for certain, but generally it is a mass of wrinkled flesh except for its mouth, the only clearly distinguishable physical attribute.

And when the predators are not gross and fleshly, they often revert to the film trope rendering of silhouette forms, such as in the game Limbo (Jensen, 2010). This entire game is in grayscale. It is two-dimensional, and even the main character is a flat, black silhouette navigating a silhouetted terrain with a gray background. In this game, spiders appear frequently, stalking the player with sharp claws - the spider can impale the character's body with a sharpened leg, wrap them in silk, and eat them if the player is too slow. But what makes it horrifying is that all we see is this silhouette. The sharp points are distinct-its fangs and claws-and the rest of it is shadow. ${ }^{10}$

Pulling it back to pen and paper, we get to see predator representations and IAR appear in graphic novels and comics, also. With the option of heavy shading available, predators can appear in extreme silhouettes where a single color has the opportunity to stand out from the rest of the form. One strong example of this is Stephen King's story "The Crate" as it appeared in his graphic novella Creepshow (1982). In one of the pages, a dark-furred predator has escaped from a chained crate and kills and devours a woman who has been a prominent character in the story. The beast has vague details on his fur, but we get his fangs and eyes in sharp clarity. In the bottom-left panel, his form blurs into the shadows. The sharpest colors are the beast's yellow eyes and the red of the woman's blood and shirt. Other examples include comic books The Dark Knight Returns and 300 (Miller, 1986, 1998), in which the predators are mostly silhouetted except for those IAR-based features in sharp color.

10 Though the trailer shows the spider for only a second, and not one with noticeable fangs, it still shows the silhouetting (timestamp 0:45): youtube.com/watch?v=Y4HSyVXKYz8 
All of these audiovisual works go through a deconstructionist approach to predator representation similar to their likenesses in strictly textual mediums. ${ }^{11}$ They all find ways to make the body of the predator almost obscure while the IAR-based features become highlighted, whether that is through a textual focus or through the use of color. One major difference between audiovisual mediums and textual mediums regarding predator representations in horror is that the audiovisual mediums express the form of the beast primarily through shading or blackness, while the textual mediums create this same vagueness through a lack of body description (other than size, occasionally).

However, both forms of representation reduce the predator to these IAR-based standards. Whether we are dealing with a meticulous writer, artist, or director, the predator becomes inherently vague in order to highlight those physical traits of the predator of which humans are instinctively afraid.

\section{Conclusion}

Through this biological-physiological lens, a statistical approach to predator descriptions in horror literature becomes not only possible but quite revealing: when creators and consumers of horror literature question what makes them terrified of predators, the portrayals of the predators become a cyclical notion. That is, as creators ask themselves how a predator can be terrifying, their instincts, whether consciously aware or not, dictate these basic forms from IAR; consumers, in turn, respond through IAR with fear because of the creator's prowess in exploiting their audiences' natural instinctive responses.

This research can be used to further our understanding of animal predators, not just as cultural tropes, but also as subconscious constructs formed as responses to audiovisual stimuli, even in literature. ${ }^{12}$ Further study could be conducted on comparisons of these descriptions in horror with horrific animals that are not predators, such as the hedge animals of Stephen King's novel The Shining (1977) or the 1986 film The Fly (Cronenberg, 1986). Researchers in social sciences can start to think interdisciplinarily about these instinctive responses to predators. When we stare into the face of the beast in cultural representations, what happens on a psychological level? What differences are there across gender, sexuality, race, class? The import of this study is that it provokes these kinds of conversations across disciplines and begs us to really ask what happens to us when we acknowledge these anatomical features and our responses to them. And beyond consumers of horror,

11 For more research on the aesthetics of predators in horror films, see the aptly named scholar Lionel Tiger's (2006) research in Further reading.

12 See Asma (2014) in Further reading for more research on human responses to fear as evidenced by horror literature. 
this research speaks to general studies of beastly encounters: when encountering animals, how do we culturally construct that animal's image in our minds, and then how do we reconstruct that image when it comes to cultural texts?

Still, when we examine these predator descriptions in horror, we are able to break them down to their bare bones: IAR-based responses to predators. Whether an intentional compositional technique or not, the ascription of the portrayals of predators in horror to instinctive reductions belies a cultural subconscious that generally fears these attributes in predators. When we consider the appearance of the predator, we are not concerned with the size of its paws. We do not even concern ourselves with the state of its fur. We are concerned with one thing only. After all, we are staring into the face of the beast.

\section{References}

Barker, C. (1991). Twilight at the towers. In Books of blood (Vol. 6, pp. 92-135). Sphere Books. Benchley, P. (1974). Jaws. Doubleday.

Benchley, P. (2002). Shark trouble: True stories about sharks and the sea. Random House.

Boone, E. (2016). The hatching. Simon \& Schuster.

Carnahan, J. (Director). (2011). The grey [Film]. Open Road Entertainment.

Carter, A. (1993). The bloody chamber, and other stories. Penguin.

Crichton, M. (1990). Jurassic Park. Alfred A. Knopf.

Cronenberg, D. (Director). (1986). The fly [Film]. 20th Century Fox.

Douglas, G. (Director). (1954). Them! [Film]. Warner Bros. Studios.

Elkayem, E. (Director). (2002). Eight-legged freaks [Film]. Warner Bros. Studios.

Hardwicke, C. (Director). (2011). Red Riding Hood [Film]. Warner Bros. Studios.

Hitchcock, A. (Director). (1960). Psycho [Film]. Shamley Productions.

Jensen, A. (Director). (2010). Limbo [Video game]. Playdead.

Kaplan, M. (2012). Medusa's gaze and vampire's bite: The science of monsters. Simon \& Schuster.

King, S. (1977). The shining. Doubleday.

King, S. (1981). Cujo. Signet.

King, S. (1982). The crate. In Creepshow. Penguin Books.

King, S. (1983). Pet sematary. Doubleday. 
Kruuk, H. (2002). Hunter and hunted: Relationships between carnivores and people. Cambridge University Press. doi.org/10.1017/CBO9780511614996

Lambert, M. (Director). (1989). Pet sematary [Film]. Paramount Pictures.

McKechnie, C. C. (2012). Spiders, horror, and animal others in late Victorian empire fiction. Journal of Victorian Culture, 17(4), 505-516. doi.org/10.1080/13555502.2012.733065

Mikami, S. (Director). (1996-2019). Resident evil [Video game franchise]. Capcom.

Miller, F. (1986). The dark knight returns [Comic book series]. DC Comics.

Miller, F. (1998). 300 [Comic book series]. Dark Horse Comics.

Miyazaki, H. (Director). (2015). Bloodborne [Video game]. Sony Interactive Entertainment.

Quammen, D. (2003). Monster of god: The man-eating predator in the jungles of history and the mind. W. W. Norton.

Rose, B. (Director). (1992). Candyman [Film]. Propaganda Films.

Rowling, J. K. (1997-2007). Harry Potter [Novel series]. Bloomsbury.

Scott, R. (Creator). (1979-2017). Alien [Film franchise]. 20th Century Fox.

Shepard, P. (1997). The others: How animals made us human. Island Press.

Simpson, C. (2010). Australian eco-horror and Gaia's revenge: Animals, eco-nationalism and the "new nature." Studies in Australasian Cinema, 4(1), 43-54. doi.org/10.1386/sac. 4.1.43_1

Spielberg, S. (Director). (1993). Jurassic Park [Film]. Universal Pictures.

Strinati, D. (2000). An introduction to studying popular culture. Routledge.

Toyama, K. (Director). (1994-2019). Silent Hill [Video game franchise]. Konami.

Traucki, T., \& Nerlich, D. (Directors). (2007). Black water [Film]. AV Pictures.

Trout, P. A. (2011). Deadly powers: Animal predators and the mythic imagination. Prometheus Books.

Wescott, E. (1989). Winter wolves. Doubleday.

\section{Further reading}

Asma, S. T. (2014). Monsters on the brain: An evolutionary epistemology of horror. Journal of Social Research, 81(4), 941-980.

Davidson, J. (2015). Reading style: A life in sentences. Columbia University Press. 
Henrich, J. (2016). The secret of our success: How culture is driving human evolution, domesticating our species, and making us smarter. Princeton University Press.

Lucic, K. (2014). Zoomorphic and anthropomorphic figures in science fiction and horror films. Hrvatski Filmski Ljetopis, 20(77-78), 12-31.

Neff, N. (2016). The belly of the beast: The uncanny shark. Gothic Studies, 18(2), 52-61. doi.org/10.7227/gs.0014

Soles, C. (2014). "And no birds sing": Discourses of environmental apocalypse in The Birds and Night of the Living Dead. ISLE: Interdisciplinary Studies in Literature and Environment, 21(3), 526-537. doi.org/10.1093/isle/isu082

Tiger, L. (2006). Torturers, horror films, and the aesthetic legacy of predation. [Open peer commentary to] Nell, V. (2006). Cruelty's rewards: The gratifications of perpetrators and spectators. Journal of Behavioral and Brain Sciences, 29(3), 244-245. doi.org/10.1017/ S0140525X06449050 
This text is taken from Human Ecology Review, Volume 25, Number 2, 2019, published by ANU Press, The Australian National University, Canberra, Australia. doi.org/10.22459/HER.25.02.2019.04 